\title{
El transporte fluvial: luces y sombras. \\ Un análisis comparativo entre sistemas de transportes para cargas en la mesopotamia argentina en pos de la multimodalidad
}

\author{
José Mateo ${ }^{1}$ \\ Ana María Ferreyra ${ }^{2}$
}

\section{RESUMEN}

Así como los metales son los mejores conductores del calor y de la electricidad, el agua lo es del comercio. Sin embargo, no siempre es posible utilizar este medio por razones obvias. Este no es el caso de la mesopotamia argentina que por definición se erige entre ríos. No obstante, el transporte fluvial es de los menos utilizados, aunque se encuentra en reciente crecimiento. El presente trabajo intenta una comparación entre tres sistemas de transporte (fluvial, ferroviario y automotor) en cinco indicadores: velocidad, costos operativos, seguridad, capacidad de carga y flexibilidad. Se concluye en la necesidad de un estudio exhaustivo que determine para la región el circuito multimodal más adecuado en tanto eficiencia y eficacia y qué cuota de sistema debería realizarse con cual modo de transporte.

Palabras clave: transporte; multimodalidad; Argentina; Mesopotamia.

\section{River transport: Lights and shadows. A cross-modal analysis of freight transport systems for} Argentina's Mesopotamia in the pursuit of Multimode.

\begin{abstract}
Just as metals are the best conductors of heat and electricity, so is water from commerce. However, it is not always possible to use this medium for obvious reasons. This is not the case of the Argentine Mesopotamia which is, obviously, located between rivers. However, fluvial transport is one of the least used, although it is in recent growth. This paper attempts a comparison between three transport systems (fluvial, railway and automotive) in five indicators: speed, operating costs, safety, load capacity and flexibility. It is concluded in the need for a thorough study that determines for the region the most suitable multimodal circuit in both efficiency and efficacy and what system quota should be made with which mode of transport.
\end{abstract}

Keywords: transportation; multimodality; Argentina; Mesopotamia

O transporte fluvial: luzes e sombras. Uma análise comparativa entre sistemas de transporte de cargas na mesopotâmia argentina em busca de a multimodalidade

\section{RESUMO}

Assim como os metais são os melhores condutores de calor e eletricidade, o mesmo acontece com a água e o comércio. No entanto, nem sempre é possível usar esse meio por razões óbvias. Este não é o caso da Mesopotâmia Argentina, que, por definição, fica entre os rios. Sim embargo, o transporte fluvial es uno de os menos utilizados, embora esteja em crescimento recente. Este artigo tenta uma comparação entre três sistemas de transporte (fluvial, ferroviário e automotivo) em cinco indicadores: velocidade, custos operacionais, segurança, capacidade de carga e flexibilidade. Conclui-se na necessidade de um estudo aprofundado que determine para a região o circuito multimodal mais adequado tanto na eficiência como na efetividade e a que quota de sistema deve ser feita com um modo de transporte determinado.

Palavras-chave: transporte; multimodalidade; Argentina; Mesopotâmia.

\footnotetext{
${ }^{1}$ Profesor Titular Universidad Nacional de Entre Rios, Argentina (InES-CONICET/FCECO-UNER) Email jamateo@fceco.uner.edu.ar

${ }^{2}$ Faculdad de Ciencias Economicas. Universidad Nacional de Entre Rios, Argentina (FCECO-UNER).
} 
"El 90\% del comercio mundial viaja por el agua. La vasta mayoría de la población mundial vive a pocos cientos de kilómetros de una costa. Cerca de tres cuartas partes del planeta están cubiertas por agua." (USCG-United States Coast Guard, 2009, p. 2)

\section{INTRODUCCIÓN}

La mesopotamia argentina, por su disposición geográfica, tuvo en los ríos la forma privilegiada de extracción de su producción e introducción de la importación. En 1875 - es decir, antes de que se iniciara el proceso de construcción de los grandes puertos de ultramar- funcionaban allí unas treinta terminales fluviales de cabotaje, constituidas por obras sumarias, cuando no simples parajes naturales, donde se realizaban operaciones de cabotaje interior con aduana, receptoría o resguardo aduanero. La corriente del comercio exterior y su concentración en los puertos mayores provocaron la extinción de algunos de estos puertos, y a finales de siglo XIX ya sumaban menos de veinte (J. Mateo, 2017a). El periodo 1915-1940, con el impulso de la agricultura ante las crisis de la Gran Guerra y la Depresión (Gravil, 1970; Nemirovsky, 1933) fue en Entre Ríos una etapa de intensa labor portuaria, cuyos casos más significativos son: sobre el río Uruguay: Unzué (Gualeguaychú) y Concordia y sobre el Paraná: Zarate, Ruíz (Gualeguay), Victoria, Diamante, Paraná, Santa Elena (puerto privado vinculado a su frigorífico) y La Paz (Poggi, 1960). En acción de fomento del cabotaje interno el Gobierno Nacional emprendió la construcción de obras fijas y flotantes - como los embarcaderos de hormigón armado- que en su época representaron un alarde de técnica constructiva. Sobre las aguas profundas del Paraná, Entre Ríos pudo planearse un sistema portuario disponiendo obras de margen en Villa Urquiza, Curtiembre, Brugo, Hernandarias y La Paz, que junto a Paraná e Ibicuy correspondían a un puerto cada 30 kilómetros en Entre Ríos sobre esa margen (Ortiz, 1943).

En la actualidad toda esta obra ha quedado rezagada u obsoleta. Algunas de ellas son hoy miradores, centros culturales, establecimientos gastronómicos o arte industrial, entre otros destinos, cuando los tiene. Un balcón privilegiado para ver correr las solitarias aguas del río a la vera de una de las cuencas económicas más importante del país ¿Cómo llegamos a esto? ¿Es posible revertirlo? ¿Vale la pena hacerlo? ¿Qué intereses componen las fuerzas que impide el avance en la agenda pública del transporte hidroviario?

La formulación de las preguntas es sencilla, como lo son generalmente aquellas que implican respuestas complejas. Cualquier análisis económico racional, con el habitual recurso del ceteris paribus, muestra la ecuación en toda su irracionalidad. Sin embargo, este comportamiento, estimamos, ha sido el producto de un polígono de fuerzas donde la 
resultante ha favorecido al automotor sobre la embarcación en el transporte interior de mercancías y personas.

El ahorro en costos de transporte que implica la navegación sobre el envío ferroviario y automotor ya no amerita discusión (Campêlo \& Duhá, 2009). La pregunta rectora de este trabajo es por qué, en un país donde la zona productiva agraria (zona-núcleo) se encuentra en torno a ríos de llanura en general navegables, el transporte hidroviario no sólo no se desarrolló, sino que tendió a su desaparición, hasta hace pocos años que parece revivir. En efecto, motorizado por la soja, las exportaciones de Bolivia y Paraguay con el uso de barcazas de empuje están pronto a alcanzar los 18 millones de toneladas anuales y se proyecta llegar a los 50 (Muñoz Menna, 2011, p. 30).

El desafío del transporte hidroviario en nuestro país sigue siendo eso, un desafío inconcluso. El objeto del trabajo presenta, como señaló Friedberg, (1993, p. 22) dos facetas interdependientes: por una parte, producir un conocimiento concreto que deriva del contexto de la acción analizada -la navegación fluvial, sus características y obstáculos- y, por otra, ayudar a los implicados a situarse en relación a ese conocimiento, y por tanto a sacar consecuencias de todo ello, integrándolo en sus prácticas, y modificándolas si fuera necesario a partir de la experiencia histórica.

\section{Antecedentes}

En su estudio clásico Georg Friedrich List argumentaba que para que un país pueda competir con otros que ya alcanzaron un elevado grado de desarrollo tecnológico, es condición sine qua non -además de proteger las industrias emergentes- la abertura de canales, la rectificación de los ríos y la creación de líneas de navegación que posibiliten que el potencial manufacturero de una nación alcance todo el territorio nacional derramando la producción industrial y agrícola. A su vez, insiste el autor, los transportes estimulan la expansión del mercado interno y abren nuevas posibilidades para el potencial manufacturero en la construcción naval, en las siderúrgicas y en los talleres mecánicos produciendo navíos y locomotoras (List, 1979, p. 259 y pass.).

List publicó su obra en 1841, en momentos en que en el Río de la Plata acababa de levantarse un bloqueo del puerto de Buenos Aires y uno de los temas más acuciantes era ya la "libre" navegación de los ríos de la Plata, Paraná y Uruguay. En efecto, uno de los argumentos centrales del llamado "proceso de organización nacional" en Argentina, giró en 
torno de las aduanas y la "libre navegación de los ríos", discusión iniciada con la desestructuración de las "Provincias Unidas del Río de la Plata" y que tuvo su primer documento en el Tratado del Pilar, establecido bajo presión de las armas en 1820 entre los estados entonces autónomos de Buenos Aires, Entre Ríos, Corrientes y Santa Fe. La problemática no cesó y volvió al ruedo en el Tratado del Cuadrilátero, en el Pacto Federal y en el Acuerdo de San Nicolás, que figuran como pactos preexistentes al momento de la sanción de la Constitución Nacional que garantizaban el libre tránsito "para todas las banderas" y un sistema de aduanas nacional periférico que anulaba las aduanas interiores.

En el desarrollo del capitalismo agrario pampeano (Sábato, 1989) la vinculación económica de la región estuvo más orientada hacia los mercados de Europa y los Estados Unidos (Fodor \& O’Connell, 1973) que a la región. El interés geopolítico y económico de los investigadores de los Estados Unidos, por la navegabilidad de la cuenca del Plata produjo una gran cantidad de investigaciones a medida que la figura de Argentina crecía en su pantalla de radar.

Ante las sensibles transformaciones en la navegación y en la arquitectura naval de finales del siglo XIX, en 1899, el gobierno argentino, concibió un extenso proyecto de mejoramiento fluvial y portuario y solicitó al gobierno de los Estados Unidos que recomendara a un ingeniero que vendría a la Argentina para asistirlo con su consejo en la formulación y ejecución de los planes. El elegido fue el ingeniero civil Elmer Corthell, quien realizó un extenso estudio en el que comparaba ambos países y asimilaba el potencial productivo de la Argentina a la de su país y a la cuenca del Plata con la del río Mississippi y resaltaba por tanto las posibilidades de navegabilidad de los ríos sudamericanos (Corthell, 1903).

Pocos años después, durante la Gran Guerra, W. S. Barclay amplió y actualizó el informe de Corthell bajo la perspectiva de la complementariedad posible entre vías fluviales y ferrovías, como las formas centrales de transporte en la región, ya que "Carreteras públicas como las de Europa y América del Norte son desconocidas. En las pampas y sabanas son simplemente la tierra encerrada entre dos vallas de alambre" (Barclay, 1917, p. 162).

Preocupados desde un punto de vista geopolítico por la injerencia de Argentina en el control de la boca de la cuenca, otro autor, William Schurz, señaló que "Su ocupación de la estratégica isla de Martín García, codiciada por Brasil, situada donde el Paraná desemboca en el estuario, le da a la Argentina una posición formidable desde punto de vista militar." Ciertamente esta isla es una posesión argentina en territorio de la República Oriental del 
Uruguay, cuya jurisdicción fue ratificada por el "Tratado del Río de la Plata y su frente marítimo" signado en Montevideo el 19 de noviembre de 1973.

El mismo autor agregaba:

“La navegación tanto en el Paraná como en el Paraguay está en gran medida en manos de empresas argentinas, aunque una empresa brasileña relacionada con el Lloyd Brasileiro opera un servicio intermitente entre Montevideo y Corumbá. Los vapores argentinos no solo navegan regularmente por el Paraguay hasta Asunción y hasta Corumbá, sino que también proporcionan al Paraná sus únicas instalaciones de transporte hasta el límite de navegación en las Cataratas de Guairá. Aunque la principal empresa de transporte que se ha hecho cargo de la flota, la famosa Mihanovich, es una sociedad anónima internacional, Argentina todavía tiene una posición predominante en materia de comunicaciones en la cuenca del Plata.”(Schurz, 1925, p. 634 la itáilica es nuestra).

Finalmente, en nuestra búsqueda de antecedentes, otro estudio de W. S. Barclay señalaba en 1932 que "Por otra parte, la exploración y el conocimiento general de la cuenca ha sido muy asistido por la introducción en los últimos tiempos de la tecnología inalámbrica de telegrafía, telefonía, el avión, y especialmente del automotor (Barclay, 1932, p. 81).

Gráfico 1 Embarcaciones que recalaron en el Puerto de Paraná entre 1910 y 1989

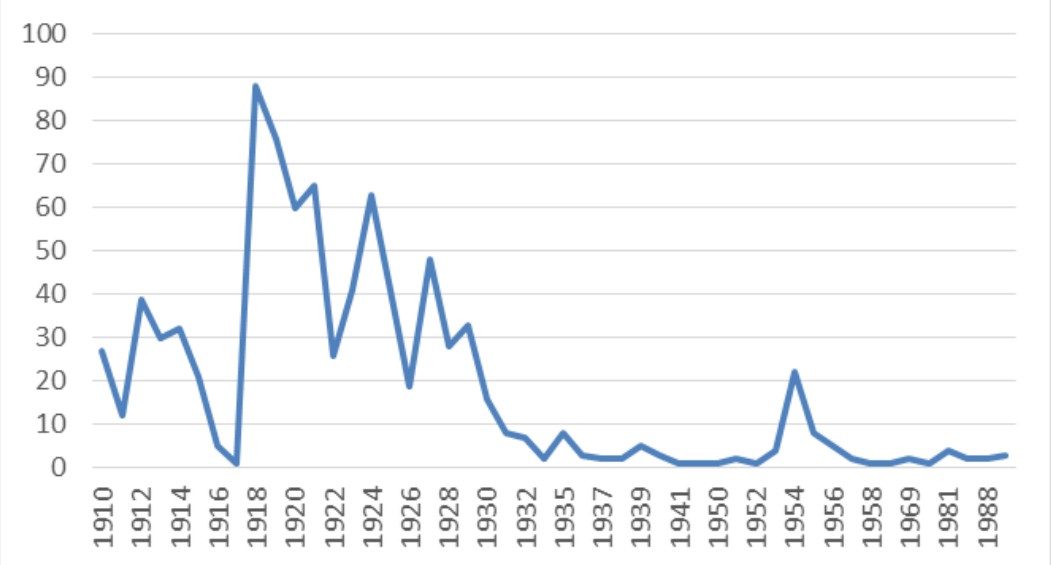

Fuente: Aduana de Paraná, Registro de exportaciones 1910-1989

A partir del ingreso de automotor en los años 1930, tras un boom que implicó que circularan miles de embarcaciones de cabotaje y varios cientos de ultramar y pasajeros entre finales del siglo XIX y principios del XX (Ortiz, 1943) los ríos navegables comenzaron a ser cada vez menos navegados. El Gráfico 1 muestra el dramatismo de este cambio en el puerto de Paraná. 
Con rarísimas excepciones, los gobernantes, en todos los niveles, han exaltado la importancia del transporte hidroviario en sus pronunciamientos públicos. Sin embargo, a la hora de la acción, de la formulación de políticas públicas, esa importancia se rinde a las presiones de intereses sectoriales, a las limitaciones presupuestarias o a las trabas burocráticas institucionales. Como resultado, la matriz del transporte en la Argentina corre siempre a contramano de la economía de costos.

\section{Definición de la problemática}

El presente trabajo es una comparación sincrónica entre diferentes variables atinentes a tres sistemas de transporte de cargas (carretero, ferroautomotor y fluvial) que tiene la intención de justificar la necesidad de avanzar en el análisis longitudinal de las políticas públicas desarrolladas o no por los diferentes gobiernos o coaliciones promotoras (Sabatier, 1988) a favor de una multimodalidad que conjugue los tres medios de transporte en sus cuotas modales óptimas.

Cada modo y cada medio de transporte ofrecen una respuesta distinta a aspectos diferenciadores de la demanda respecto a la rapidez, los costos, la seguridad, la capacidad y la flexibilidad, lo que, como afirma Roberto Bloch, “...no solo permite, sino que aconseja servir a la demanda mediante un sistema integrado de transportes" (Bloch, 1999, p. 16).

En tal sentido, este ensayo se refiere explícitamente a la fase de determinación del problema a definir políticamente como público (Knoepfel, Larrue, Varonne, \& Hinojosa Dieck, 2007, p. 12). ${ }^{3} \mathrm{Y}$ en tal sentido a abogar por un desarrollo de la intermodalidad entre sistemas de transporte en lugar de la clásica competencia entre ellos - como ha sido el caso de la historia del transporte en Argentina, donde el ferrocarril abolió a la navegación de cabotaje y el camión a ambos luego (J. Mateo, 2007). Adherimos entonces a afirmar la generalización en lo referente a considerar a los sistemas de transporte como complementarios entre sí y no competitivos según el tramo de los flujos de mercancías. El tipo de generalización es descriptiva, a través de la presencia de datos y la descripción de la implementación de los diversos sistemas de transporte, buscando demostrar el efecto beneficioso que trae para la

\footnotetext{
${ }^{3}$ Una de las definiciones más completas de las políticas públicas, de las tantas que existen, a nuestro entender es aportada por estos autores quienes afirman que ellas son "una concatenación de decisiones o de acciones, intencionalmente coherentes, tomadas por diferentes actores, públicos y ocasionalmente privados —cuyos recursos, nexos institucionales e intereses varían-, a fin de resolver de manera puntual un problema políticamente definido como colectivo", la cual integra tanto las vertientes top-down y botton-up, como a las coaliciones promotoras o de causa con el esquema clásico de ciclo.
} 
región el uso del transporte fluvial en los tramos centrales del flujo. El tiempo del trabajo es en este caso sincrónico, o de una franja de temporalidad reducida dada la heterogeneidad de los datos, pero con el desarrollo de investigaciones ulteriores pretendemos determinar las políticas públicas desarrolladas o no para implementar la navegación fluvial en comparación con las del resto de los sistemas de transporte desde la aplicación de las políticas neoliberales y neodesarrollistas. ${ }^{4}$

Los casos seleccionados para el siguiente trabajo son, como puede desprenderse de lo ya mencionado, el transporte de mercancías a través de camión, ${ }^{5}$ ferrocarril y convoyes fluviales.

Específicamente nos referiremos los sistemas utilizados para transportarlas por parte de los países que comparten la vía de la hidrovía Paraguay-Paraná (HPP), la cual es el eje de circulación de mercancías provenientes de los cinco países que componen la Cuenca del Plata (Argentina, Brasil, Bolivia, Paraguay y Uruguay) y que han hecho una utilización diferencial de la vía fluvial.

Primeramente, observaremos cómo dichos sistemas son utilizados por diferentes países y cuál es la relación entre economías más desarrolladas con respecto a los mayores productores agrarios de la hidrovía (Argentina y Brasil):

Cuadro 1 Cuota modal de sistemas de transporte en diferentes países para todas las mercancías.

\begin{tabular}{|l|l|l|l|l|l|}
\hline País & Hidrovías \% & Ferrovías \% & Carreteras \% & Superficie (millones de & \% de uso de hidrovía// \\
\hline USA & 25 & 50 & 25 & 9,8 & 2,6 \\
\hline Canadá & 35 & 52 & 13 & 10 & 3,5 \\
\hline Rusia & 13 & 83 & 4 & 17,1 & 0,8 \\
\hline Alemania & 29 & 53 & 18 & 0,357 & 81,2 \\
\hline Brasil & 13,9 & 25,6 & 60,5 & 8,5 & 1,6 \\
\hline Argentina & 1,5 & 14,5 & 84 & 2,8 & 0,5 \\
\hline
\end{tabular}

Fuente: elaboración propia en base a Campêlo \& Duhá, (2009) y Bolsa de Cereales de Entre Ríos, (2012)

Como podemos observar en el Cuadro 1, el transporte carretero es el menos utilizado en las grandes economías seleccionadas mientras que éste es el preponderante en Brasil (menos dotado que Argentina de ríos de llanura al menos en su zona productiva más

\footnotetext{
${ }^{4} \mathrm{Si}$ bien aceptamos que este sería un aspecto más adecuado de comparación aún no contamos con los datos suficientes para ellos.

5 Desde hace algunos años se viene experimentando con la utilización de "bitrenes". Un bitrén o tren de carretera, básicamente, es un camión tractor con dos semirremolques apoyados sobre nueve ejes, dotado con EBS (sistema electrónico de frenado), ESP (sistema electrónico de estabilidad), frenos ABS, balanza de control de peso por eje, suspensión neumática y luces LED. Mientras que un camión normal puede cargar hasta 45 toneladas brutas, estos pueden llevar 75 toneladas y ahorrar un $25 \%$ de combustible. Sin embargo, este medio requiere rutas habilitadas y si bien reduce no anula la mayoría de los indicadores a analizar.
} 
dinámica) y prácticamente hegemónico en el caso de Argentina que cuenta con ríos navegables en la zona de mayor producción agraria.

Por su parte podemos también presentar un ranking de los diez países que utilizan mayormente las aguas continentales para el transporte de sus mercancías:

Cuadro 2 Top 10 de países con transporte de cargas en aguas continentales (en miles de toneladas)

Fuente: ITF (2015)

\begin{tabular}{|l|l|l|l|}
\hline Países & 2006 & 2009 & 2012 \\
\hline China & $1.290,85$ & $1.803,27$ & $2.829,55$ \\
\hline USA & 486 & 406,61 & 464,67 \\
\hline Rusia & 86,73 & 52,69 & 80,76 \\
\hline Alemania & 63,98 & 55,5 & 58,49 \\
\hline Países Bajos & 43,58 & 35,64 & 47,52 \\
\hline Canadá & 24,8 & 21,06 & 26,3 \\
\hline Rumania & 8,16 & 11,76 & 12,52 \\
\hline Bélgica & 8,97 & 7,09 & 10,42 \\
\hline Francia & 7,95 & 7,42 & 7,74 \\
\hline India & 2,86 & 3,71 & 3,06 \\
\hline
\end{tabular}

Como puede observarse en el Cuadro 2, entre 2006 y 2012 solo Alemania ha reducido el volumen de carga por este medio

No contamos con información al momento del resto de los casos de la cuenca, pero consideramos estas proporciones altamente significativas. Lo que sí podemos dimensionar es el desarrollo de la navegación fluvial en los últimos años de cada uno de los cinco países rivereños.

Cuadro 3 Remolcadores, barcazas y capacidad de carga en la hidrovía Paraná-Paraguay en el año 2005.

\begin{tabular}{|l|l|l|l|l|l|l|l|}
\hline \multirow{2}{*}{ Bandera } & \multicolumn{2}{|l|}{ Remolcadores } & Barcazas & Capacidad & Rotación Med & Convoyes & Capacida \\
\cline { 2 - 8 } & Número & Potencia $(\mathrm{h}$ & Número & TPB & Días & $\begin{array}{l}\text { Barcazas pr } \\
\text { convoy }\end{array}$ & Ton/año \\
\hline Paraguay & 49 & 127.998 & 393 & 605.594 & & & \\
\hline Bolivia & 17 & 52.250 & 334 & 534.540 & & & \\
\hline Argentina & 25 & 45.496 & 141 & 211.274 & & & \\
\hline Brasil & 19 & 17.650 & 72 & 106.460 & & & \\
\hline Panamá & 3 & 10.800 & 21 & 35.400 & & & \\
\hline Uruguay & 0 & 0 & 12 & 19.200 & & & 12.512 .8 \\
\hline Total & 113 & 264.194 & 973 & 1.512 .468 & 30 & $16-30$ & \\
\hline
\end{tabular}

Fuente: Carlos Emilio Pavan, (2012, p. 71).

El Cuadro 3 nos permite varias reflexiones al respecto. El transporte fluvial requiere de una unidad tractora (el remolcador) y una unidad contenedora (la barcaza). Este conjunto se organiza en combinaciones de $4 \times 4$ o $5 \times 6$ barcazas por remolcador, lo que lleva a 
la conformación de trenes de empuje de 16 o 30 barcazas cada uno. Gran parte de las flotas paraguaya y boliviana de la HPP están integradas por embarcaciones de propiedad de armadores argentinos. En Paraguay, por tener bandera genuina, entre otros requisitos estos armadores tienen que tener domicilio en Paraguay, formando una nueva empresa asociados con empresas paraguayas. Para obtener bandera boliviana los armadores extranjeros deben registrar los buques en el Registro Internacional Boliviano de Buques (RIBB) e instalar una representación con domicilio en Bolivia. ${ }^{6}$

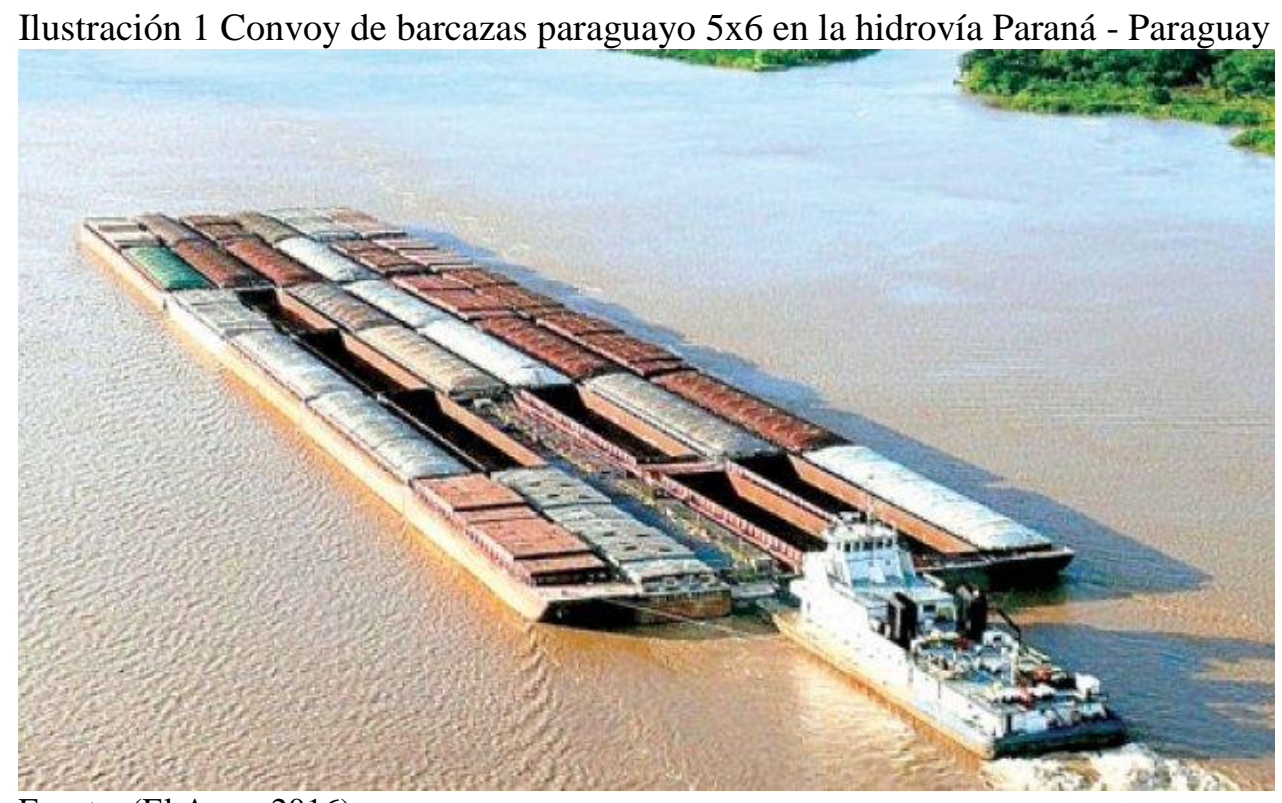

Fuente: (El Agro, 2016)

La imagen anterior fue publicada por el periódico paraguayo El Agro el 16 de febrero de 2016 bajo el título "La flota mercante más grande de la hidrovía está bajo dominio paraguayo", dando entidad a las cifras del Cuadro 3. En efecto, la bandera paraguaya flameaba en el $40 \%$ de los convoyes de barcazas en 2005 y por lo visto ese número se ha sostenido o incrementado. Por su parte, Argentina solo usufructuaba el $14 \%$ del total. ${ }^{7}$

A continuación, abordaremos el análisis comparativo de los sistemas de transporte seleccionados, a partir de las siguientes dimensiones y en principio sin ponderar ni jerarquizar:

\footnotetext{
6 El Registro Internacional Boliviano de Buques fue creado en el año 2000 con sede en La Paz; en el 2012 contaba con 68 buques inscriptos en el ámbito marítimo y 295 embarcaciones en el ámbito fluvial.

${ }^{7}$ Una aclaración adicional: la presencia de banderas panameñas e incluso bolivianas no debe llevar a error. Se trata de las llamadas "banderas de conveniencia", que raramente implican una relación entre ésta y el país que representan. Panamá es uno de los mayores "dadores de bandera" del mundo y si bien Bolivia lo es en menor medida también cuenta con un registro off shore de bandera (J. Mateo, 2015).
} 
A. Velocidad: Implicará una estimación en función de la distancia recorrida por unidad de tiempo para una misma carga según el sistema utilizado.

B. Costos de operación: Serán evaluados en función de los atenientes al combustible utilizado, la fuerza de trabajo necesaria, los valores para cada uno de los conjuntos de transporte, la vida útil de los artefactos de transporte, los sistemas de peaje, etc. Además, se considerarán las externalidades negativas ambientales y de mantenimiento de cada sistema.

C. Seguridad: Estará dada en cada caso por los riesgos que implican cada sistema en función de sus características y su correlato en la contratación de seguros.

D. Capacidad de carga: Implicará el volumen de carga transportado en una sola operación para un mismo tipo de carga.

E. Flexibilidad: Consideraremos aquí la ductilidad de los sistemas para el acceso desde las zonas de producción hasta su destino final y la documentación pertinente en cada caso.

\section{A. La velocidad}

En el caso de la velocidad el transporte ferroviario toma la delantera (Cuadro 4) y hemos sido conservadores en cuanto a la velocidad crucero desarrollada en función de la realidad de la infraestructura ferroviaria argentina.

Cuadro 4 Velocidad de crucero de los diferentes sistemas de transporte.

\begin{tabular}{|l|c|c|}
\hline \multicolumn{1}{|c|}{ Medio } & Velocidad crucero & Índice \\
\hline Fluvial & $24,076 \mathrm{~km} /$ hora $^{8}$ & 100 \\
\hline Ferroviario & $100 \mathrm{~km} / \mathrm{hora}$ & 417 \\
\hline Caminero & $90 \mathrm{~km} / \mathrm{hora}$ & 375 \\
\hline
\end{tabular}

Fuente: Elaboración propia y datos de la Bolsa de Comercio de Rosario (BCR, 2011)

Al margen de las mayores velocidades que desarrolla este medio de transporte, en comparación con el transporte por carretera, además, evita los problemas de la congestión de tráfico. Esta virtud es compartida a su vez con la navegación fluvial. El ferrocarril a su vez no requiere detenerse entre estaciones o hacer paradas técnicas o de descanso de sus conductores.

El transporte fluvial puede verse demorado por los niveles del río en relación con su calado o por la imposibilidad de navegar de noche en tramos mal señalizados. Sin embargo, los ferrocarriles comparten la misma vía férrea, y si esta es utilizada para pasajeros éstos tienen la prioridad.

\footnotetext{
${ }^{8} 13$ millas náuticas por hora.
} 
En este contexto, y una vez cargados, para transportar 24.000t a una distancia equis se requerirán un solo convoy de empuje, 15 formaciones de ferrocarril de 40 vagones cada uno despachadas en un mismo sentido y 727 camiones uno tras otro en la carretera. Si traducimos esto a una dimensión espacial tenemos la utilización simultánea del Cuadro 5.

Cuadro 5 Utilización de espacio para 24.000 t.

\begin{tabular}{|l|l|l|}
\hline Medio & Kilómetros & índice \\
\hline Convoy de barcazas & $0,3 \mathrm{~km}$ de río & 100 \\
\hline Ferrocarriles & $8,8 \mathrm{~km}$ de vía & 2933 \\
\hline Camiones & $16 \mathrm{~km}$ de carretera & 5333 \\
\hline
\end{tabular}

Fuente: elaboración propia en base a datos de Carlos Emilio Pavan, (2012, p. 60)

El espacio entonces agrega un problema adicional al tiempo de circulación con la acumulación de camiones, verdaderos "silos sobre ruedas" (González Climent, 1993), que utilizan el mismo sistema carretero que el resto del transporte público y privado y a la espera de la descarga generan aglomeraciones, interminables colas, y concentraciones poco saludables: como "El triángulo" en Bahía Blanca y el llamado popularmente "El chiquero" en Quequén (J. Mateo, 2017b), etc. El 58\% del volumen de las exportaciones argentinas (y 31\% de su valor) tienen lugar en la franja costera del Gran Rosario. Esto lleva a que en el norte de Rosario suelen conformarse colas de camiones de más de $15 \mathrm{~km}$. de extensión en la temporada alta, y el tránsito promedio diario en las carreteras de acceso llega a 12.000 vehículos diarios (Bárbero, J.A. Serebrisky, 2007). Este aspecto implica una nueva reflexión acerca de este indicador, sumado a los legítimos reclamos sindicales que suelen ser más frecuentes en el caso de los conductores de camiones que en el de los que actúan en los otros sistemas.

\section{B. Los costos operativos}

Es sin duda el indicador más fuerte a favor del transporte fluvial. Y no es ni mucho menos un tema menor. El trasporte, como es sabido, produce impactos sobre el valor de la exportaciones que suelen ser muy superiores a los gravámenes arancelarios (García Rodríguez, 2009, p. 29). Por ejemplo, el BID considera que una reducción del $10 \%$ en los costos del trasporte tendría un efecto cinco veces superior que una reducción arancelaria del 10\% (SELA, 2011, p. 5). Podemos deducir de esto que el impacto también se reflejaría en el mercado interior. La potencia requerida de motores, que incide directamente sobre el consumo de combustibles, señala claramente el ahorro de energía desplegada por cada medio (Cuadro 6). 
Cuadro 6 Potencia requerida de motores (hp) para movilizar $24.000 \mathrm{t}^{9}$

\begin{tabular}{|l|l|l|}
\hline Medio & $\mathrm{Hp}$ & índice \\
\hline Fluvial & 6 & $100 \%$ \\
\hline Ferro carretero & 48 & $800 \%$ \\
\hline Caminero & 160 & $2667 \%$ \\
\hline
\end{tabular}

Fuente: Elaboración propia con datos del Comité Central de Navegación Interior de Alemania (Zentralkomitee der Binnenschifffahrt, MTU Binnenschiffe, 2017)

La movilización resulta entonces ocho veces más onerosa en energía desplegada por parte del transporte ferroautomotor y más de veintiséis veces utilizando el camión. Estos porcentajes se verifican y se incrementan al analizar el consumo de combustibles como podemos apreciar en el Cuadro 7:

Cuadro 7 Rendimiento de combustible para transportar $24.000 \mathrm{t}$ a $500 \mathrm{~km}$

\begin{tabular}{|l|l|l|}
\hline Medio & Litros de gasoil & índice \\
\hline Remolcador de empuje & 2,4 & 100 \\
\hline Locomotora & 89,1 & 3713 \\
\hline Camión & 127,2 & 5300 \\
\hline
\end{tabular}

Fuente: Jorge Bianchi, (2015, p. 13) y Puntoazul gasolineras, (2014). ${ }^{10}$

El combustible es el mismo para todos los medios de transporte y las cifras son elocuentes por sí mismas.

Si pasamos al uso de fuerza de trabajo necesaria para cada sistema los costos dan una leve preeminencia al ferrocarril sobre el convoy. Hemos elaborado el Cuadro 8 que muestra lo mano de obra intensivo que resulta el transporte carretero.

Cuadro 8 Mano de obra utilizada para 24.000 toneladas transportadas a $500 \mathrm{~km}$

\begin{tabular}{|l|l|l|l|l|l|l|l|}
\hline Medio & Distancia & Velocidad (b) & $\mathrm{a} / \mathrm{b}$ & $(\mathrm{a} / \mathrm{b}) / 8 \mathrm{~h}$ & $\begin{array}{l}\text { Cantidad de } \\
\text { operarios/jornadas }\end{array}$ & Jornales & Índice \\
\hline Remolcador & 500 & 11 & 45 & 5,7 & 311 & 17 & 100 \\
\hline Locomotora & 500 & 100 & 5 & 0,6 & 1712 & 11 & 62 \\
\hline Camión & 500 & 90 & 6 & 0,7 & $1454^{13}$ & 1010 & 5924 \\
\hline
\end{tabular}

Fuente: elaboración propia en función de los datos y fuentes precedentes

\footnotetext{
${ }^{9}$ Los datos originados por el Comité Central de Navegación Interior de Alemania indican que con un hp de potencia se pueden arrastrar $4000 \mathrm{~kg}$ sobre el agua, $500 \mathrm{~kg}$ sobre rieles, $150 \mathrm{~kg}$ sobre ruedas y $6 \mathrm{~kg}$ sobre el aire. ${ }^{10}$ Este autor señala que con un galón de combustible (3,8 litros) un remolcador puede transitar 800 kilómetros, una locomotora 320. Un camión por su parte consume -el dato es para Europa- dependiendo de su tamaño, entre 30 y 40 litros cada 100 kilómetros, adoptamos 35 litros cada $100 \mathrm{~km}$, cifra que nos resultan algo conservadoras, pero sirven para la comparación.

${ }^{11}$ Capitán, un Jefe de Máquinas y un marinero.

${ }^{12}$ Considerando trenes de hasta 40 vagones, un maquinista y un ayudante por cada uno. A estos hay que sumarle todo el personal de estación.

${ }^{13}$ Considerando dos operarios por camión en 127 camiones. Aún si suponemos la autoexplotación de utilizar un solo conductor por camión las cifras también son elocuentes.
} 
Y decimos que se equiparan porque al ferrocarril se le agrega todo el personal de estación, aunque el ferrocarril pasa sin detenerse por la mayoría de ellas salvo que tenga que repostar combustible. En cuanto al mantenimiento de la vía de traslado no tenemos datos por kilómetro entre las operaciones y costos de dragado y balizamiento y mantenimiento de vías y asfalto.

En lo referente a los peajes las embarcaciones lo pagan al sur de Santa Fe y los camiones en gran parte del recorrido según la ruta que tomen (lo cual afecta a la velocidad crucero), no así el ferrocarril.

Otro aspecto que considerar en relación con los costos son los valores de cada unidad de tracción y de carga. En tal sentido estimamos para 24.000t un convoy con un remolcador para el caso fluvial, 15 formaciones de ferrocarril con 40 vagones cada uno y 727 camiones con remolcador.

Como podemos ver en el Cuadro 9 la amortización del capital invertido es dos veces y media superior en los trenes de empuje, y tres veces y media en relación con el transporte carretero por camión.

Cuadro 9 Valor y vida útil de los vehículos tractores y traccionados para $24.000 \mathrm{t}$

\begin{tabular}{|l|l|l|l|l|l|}
\hline Medio & Unidades & Euros (a) & índice & Vida útil en años (b) & índice \\
\hline Remolcador/Barcaza & $1 / 16$ & 6135456 & 100 & 50 & 100 \\
\hline Locomotora/vagones & $15 / 600$ & 15338748 & 250 & 30 & 60 \\
\hline Chasis/tráiler & 727 & 22302179 & 363 & 10 & 20 \\
\hline
\end{tabular}

Fuente: Elaboración propia según datos de Constantino y Paul Georgescu (Georgescu \& Georgescu, 1998) y Comité Central de Navegación Interior de Alemania (Zentralkomitee der Binnenschifffahrt, MTU Binnenschiffe, 2017)

Todos estos aspectos afectan las tarifas en los transportes. Como vemos en el cuadro 10, el valor de los fletes ferroviarios duplica al fluvial y el transporte carretero lo cuadruplican.

Cuadro 10 Valor de las tarifas de transporte para transportar $24.000 \mathrm{t}$ a $500 \mathrm{~km}$.

\begin{tabular}{|l|l|l|l|}
\hline Medio & Tarifa $\mathrm{t} / \mathrm{km}(\mathrm{u} \$ \mathrm{~d})$ & Tarifa total $(\mathrm{u} \$ \mathrm{~d})$ & Índice \\
\hline Remolcador/Barcaza & 0,02 & 240000 & 100 \\
\hline Locomotora/vagones & 0,04 & 480000 & 200 \\
\hline Chasis/tráiler & 0,08 & 960000 & 400 \\
\hline
\end{tabular}

Fuente: Elaboración propia con datos de BCR, (2011)

Finalmente considerando las externalidades negativas que implican el impacto sobre el medio ambiente, tenemos que por unidad tractora el medio fluvial también es el menos contaminante (Cuadro 11). 
Cuadro 11 Emisión de gases por medio de transporte por unidad tractora

\begin{tabular}{|l|l|l|l|l|}
\hline Medio & Hidrocarburos & Monóxido de Carbono & Óxido nitroso & índice \\
\hline Barcaza & 0,040 & 0,090 & 0,240 & 100 \\
\hline Ferrocarril & 0,208 & 0,290 & 0,830 & 359 \\
\hline Camión & 0,285 & 0,861 & 4,613 & 1247066 \\
\hline
\end{tabular}

Fuente Helman et al.,( 2002)

\section{C. $\underline{\text { La seguridad }}$}

Este es uno de los aspectos más cualitativos de los analizados. En cada sistema está relacionado directamente con el tiempo de utilización del medio por la cantidad de unidades utilizadas. El convoy de empuje por sus características se trata de barcazas de doble fondo con cámara de aire entre ellos y agrupadas en conjuntos de 16 a 30 unidades que se encuentran fijadas al remolcador y actúan como flotadores de este, los riesgos de siniestralidad se reducen a alguna colisión, encallado por falta de calado o incendio. Al transportar grandes cantidades de carga por convoy a baja velocidad, con medidas de seguridad que exceden a los otros medios controlados en Argentina por la Prefectura Nacional (REGINAVE, 1973), por más de realizar recorridos amplios consideramos que se trata de un medio de siniestralidad baja o muy baja.

Los ferrocarriles por su parte también tienen estadísticamente baja siniestralidad a pesar de desarrollar velocidades más altas. Los riesgos son también la colisión o el incendio y se suma el descarrilamiento. Si bien los casos registrados de alguno de estos incidentes son bajas, los efectos suelen ser sobre las vidas y sobre las mercancías transportadas los más graves de todos los sistemas de transporte. Aun así, consideramos que el transporte ferroviario tiene una siniestralidad baja.

En el transporte carretero la siniestralidad aumenta considerablemente. Según datos de Centro de Experimentación, Investigación y Seguridad Vial que asesora a las ocho principales aseguradoras de Argentina, sobre un análisis de 4000 casos, el 23\% de los accidentes son protagonizados por camiones y el $77 \%$ en rutas y casi la mitad es frontal lo que reduce mucho la siniestralidad en autopistas. En el 95\% de los casos la causa del siniestro es causada por el conductor. Esto implica otra reflexión: las rutas son compartidas por camiones, automóviles de diferente porte y estructura y motocicletas, lo que incrementa el riesgo estadístico de siniestro.

Otro dato no menos curioso es la distribución espacial de estos accidentes:

Gráfico 2 Porcentaje de siniestralidad carretera por provincia 


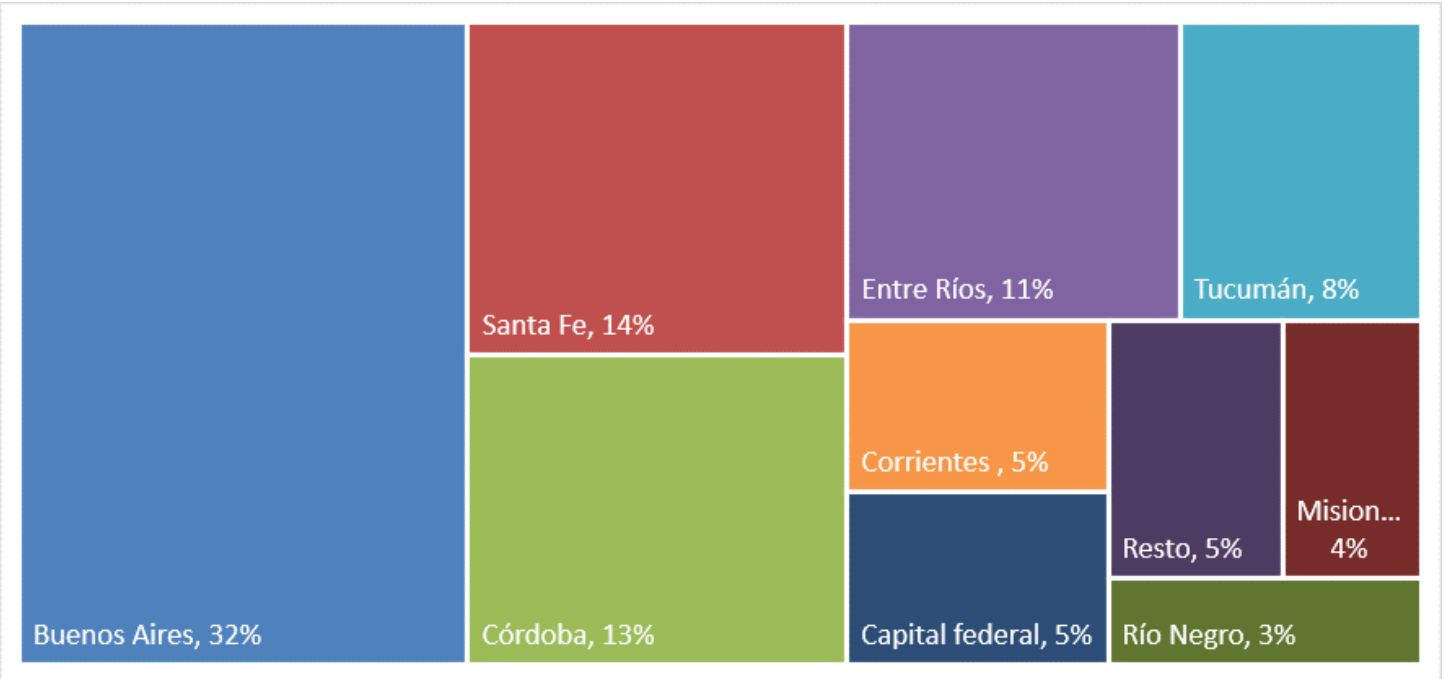

Fuente: Centro de Experimentación, Investigación y Seguridad Vial (https://www.cesvi.com.ar/index2.html)

La siniestralidad se concentra en un $20 \%$ en las provincias de la mesopotamia y un $51 \%$ entre las provincias de Santa Fe, Buenos Aires y CABA, todas las vías de flujo carretero de la "zona-núcleo".

Al margen de los accidentes (colisión, incendio, despiste y vuelco) de los camiones que se multiplica por la cantidad de vehículos utilizados por unidades de carga estos son pasibles de robos por parte de los denominados "piratas del asfalto", riesgo que no registran (al menos en este siglo) el transporte fluvial y ferroviarios. Es entonces que podemos comparativamente calificar a la siniestralidad alta o muy alta.

El Cuadro 12 sintetizan estas apreciaciones sobre siniestralidad, la cual no hemos ponderado por carecer datos que nos ayuden a hacerlo.

Cuadro 12 Siniestralidad estimada por medio de transporte

\begin{tabular}{|l|l|}
\hline Medio & Siniestralidad \\
\hline Fluvial & Baja a muy baja \\
\hline Ferroviario & Baja \\
\hline Carretero & Alta a muy alta \\
\hline
\end{tabular}

Fuente: elaboración propia

\section{La capacidad de carga}

Este es otro aspecto que otorga ventajas competitivas para el transporte fluvial. Las barcazas son una especie de plataformas flotantes cuya estructura está hecha de acero. Entre sus características se cuentan las siguientes: considerable capacidad de carga (tanto líquida como seca), bajo costo de producción, rapidez en su construcción y puesta en funcionamiento; el mantenimiento es económico y, por su forma geométrica, también son fáciles de maniobrar ya sea en ríos, mares, costas, lagunas, bahías, puertos o laderas. 
Por lo regular en la hidrovía se utilizan barcazas "tipo Mississippi" de 1500 toneladas de carga cada una, sin embargo, como afirma Carlos Emilio Pavan, (2012b, p. 14) se encuentran diseñadas barcazas "tipo Paraná” que duplicarían esa capacidad de carga por unidad. A pesar de ello hemos utilizado la barcaza tipo de 1.500 t que de momento es la más utilizada. El Cuadro 13 sintetiza en cantidad de unidades portantes para transportar $24.000 \mathrm{t}$.

Cuadro 13 Capacidad de carga para 24.000 t.

\begin{tabular}{|l|l|l|}
\hline Medio & Unidades necesarias & índice \\
\hline Barcazas $(1.500 \mathrm{t} \mathrm{c} / \mathrm{u})$ & 16 & 100 \\
\hline Vagones $(40 \mathrm{t} \mathrm{c} / \mathrm{u})$ & 600 & 3750 \\
\hline Camiones $(33 \mathrm{t} \mathrm{c} / \mathrm{u})$ & 727 & 4544 \\
\hline
\end{tabular}

Fuente: elaboración propia en base a datos de Carlos Emilio Pavan, (2012, p. 60)

Como se puede observar se pueden transportar la totalidad de las $24.000 \mathrm{t}$ en un solo convoy $4 \times 4$, mientras, repetimos, se necesitarían 15 formaciones ferroviarias y 727 camiones o 534 camiones con acoplados, ya que el peso máximo permitido para trasmitir a la calzada en carreteras es de 45t por unidad (Decreto 79/98).

El camión es siempre el primer medio de transporte y regularmente el último, sea este en el país (si es para consumo o procesamiento local) o en el exterior (si se exportan commodities como soja, trigo, maíz). Si se procesa, por ejemplo, harina o aceite requerirá una reexportación hacia puerto o hacia la fragmentación para el comercio mayorista y minorista, para finalmente llegar al consumidor.

Un detalle adicional no menor es la necesidad bastante regular con el desarrollo de la arquitectura naval de realizar una primera carga en algún puerto concentrador $(h u b)$, por ejemplo, el de Rosario, que se transforma en alimentador (feeder) de otro, por ejemplo Quequén o Bahía Blanca (BCR, 2011), que por razones de calado y de francobordo (carga máxima que puede admitir un buque en razón de las aguas, menor en las menos salobres) que se transforma en hub para completar la carga del buque (toping off) y de allí generar la exportación. Si el puerto de Quequén o de Bahía Blanca no contara en su hinterland con la mercancía en variedad y cantidad de la carga inicial, esto requeriría nuevos traslados carreteros o ferroviarios, aunque existen trenes de barcazas marítimas.

A su vez, en el caso específico del transporte fluvial por los ríos Paraná y Uruguay, el tráfico de bajada supera cuatro veces al de subida, y el $80 \%$ de este último corresponde a los combustibles. Sin embargo, este factor consideramos aplica por igual o en forma similar al resto de los sistemas de transporte. La diferencia a favor del sistema fluvial es 
que un mismo tren de empuje pude transportar por su capacidad a varias barcazas e incluso remolcadores como se puede apreciar en la Ilustración 2.

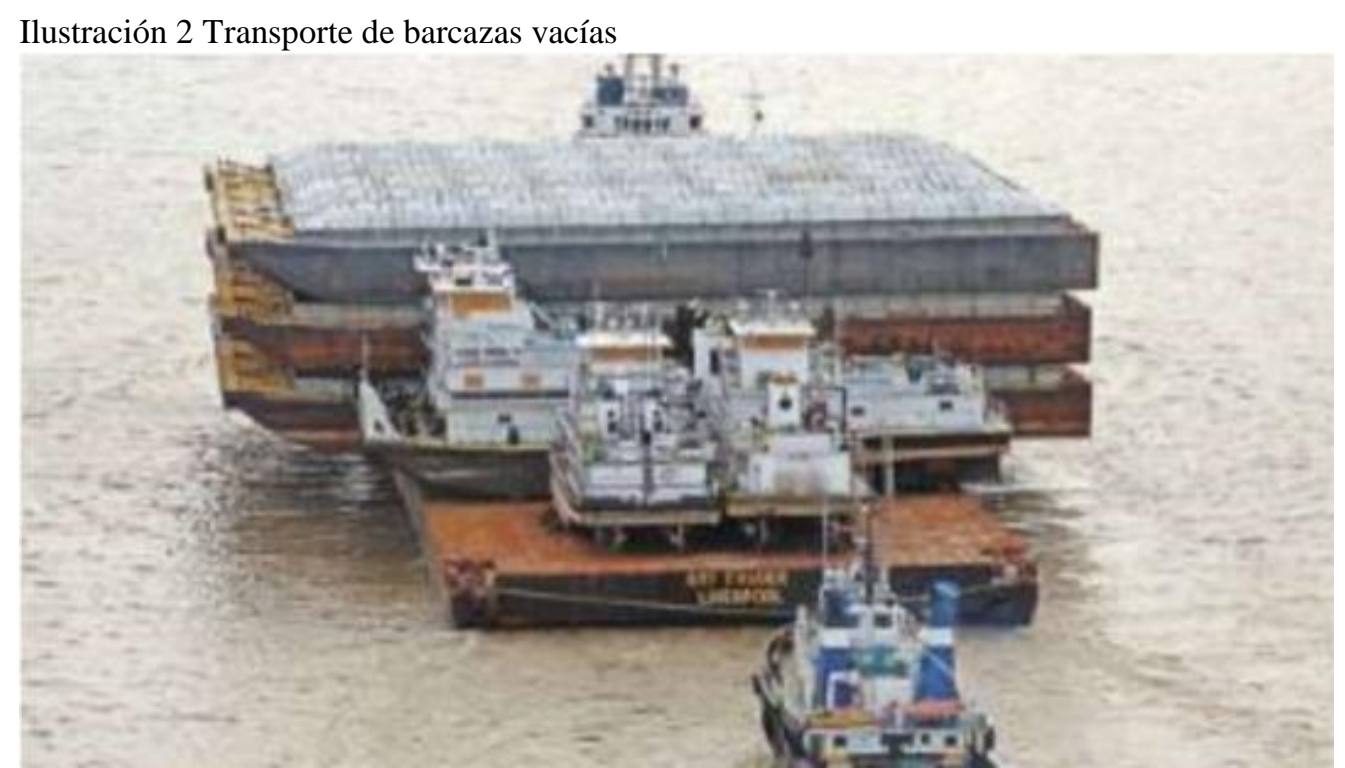

Fuente: Carlos Emilio Pavan, (2012b, p. 92)

Es decir, el combustible y la fuerza de trabajo se usan en el caso del ferrocarril y del camión de ida y de vuelta, en el caso de la barcaza es posible ahorrar ambos en la vuelta.

\section{E. La flexibilidad}

El transporte fluvial requiere regularmente, al igual que el ferrocarril, un traslado previo y posterior en camión. Podemos decir que mientras el camión puede producir un transporte puerta a puerta (o de "tranquera" a acopio y de este a otro destino) esto no lo pueden realizar los otros dos medios de transporte. Sin embargo, para el transporte de graneles esto no es exactamente así. Como hemos visto en el acápite anterior para el caso del medio fluvial suele realizarse un traslado en camión desde el establecimiento productivo al silo del acopiador, otro desde allí al puerto y otro fluvial hasta el puerto de exportación donde la carga puede ir directamente a la embarcación exportadora o a silo portuario.

En el caso del ferrocarril también hay un transporte carretero del establecimiento productivo al silo de acopiador o de estación y de allí debe realizar maniobras dentro del puerto o recurrir a camiones para el tramo final y descargar en silo portuario (J. Mateo, 2009, p. 195). 
Si el transporte se realizara totalmente por camión, difícilmente este se realizaría desde el lugar de producción al de consumo a no ser que fuera para el mercado interior (a molinos, aceiteras, etc.).

El transporte fluvial reduce las operaciones de carga y sobre todo de descarga ya que una manga aspiradora trabaja sobre un volumen superior de carga en relación otros medios de transporte.

En el caso de Argentina se ha difundido un método novedoso conocido como "silo bolsa" el cual permite al productor acopiar sin necesitar onerosas instalaciones como los silos metálicos o de mampostería, y con un simple "sinfín" cargar los camiones. La descarga en silo portuarios en el caso del camión se hace por volcado y aspiración debiendo esperar el camión su turno luego de aprobada la calidad y variedad del producto para una carga homogénea en los bulk carriers (buques graneleros).

Finalmente, un aspecto que afecta la flexibilidad y que a nuestro parecer se encuentra en la raíz del desuso que se hace del transporte fluvial son aquellos vinculados a los aspectos institucionales implícitos en los diferentes modos de transporte. Este factor aplica a la documentación que deben llevar -y el trámite que debe realizar para obtenerlo- el vehículo portante sobre sí mismo, la documentación sobre la carga portada y la operatoria logística sobre la carga.

En el Cuadro 14 podemos observar el primero de estos indicadores.

Cuadro 14 Documentación del vehículo convoy de barcazas/camión

\begin{tabular}{|c|c|c|}
\hline \multicolumn{3}{|c|}{ Documentación según medio de transporte } \\
\hline Convoy de empuje & Transporte ferroviario & Transporte carretero \\
\hline Título de propiedad & & $\begin{array}{l}\text { Título o cédula de propieda } \\
\text { vehículo }\end{array}$ \\
\hline Seguro de la embarcación & & Seguro de automotor \\
\hline $\begin{array}{l}\text { Libro Registro de Inspecciones de } \\
\text { Seguridad }\end{array}$ & $\begin{array}{l}\text { Certificado de } \\
\text { habilitación firmado por el representa } \\
\text { técnico de la empresa concesionaria }\end{array}$ & $\begin{array}{l}\text { Revisión técnica vehicular } \\
\text { (anual o semestral según } \\
\text { antigüedad del vehículo) }\end{array}$ \\
\hline Diario de navegación & $\begin{array}{l}\text { Certificado de despacho escrita de los } \\
\text { de estación expresando el número } \\
\text { del tren, la hora de su salida y la estad } \\
\text { que se dé aviso. }\end{array}$ & \\
\hline & $\begin{array}{l}\text { Boleto de precaución } \\
\text { en el que se avisará que un tren corre } \\
\text { adelante (otorgada por el jefe de estad }\end{array}$ & \\
\hline $\begin{array}{l}\text { Certificado de seguridad de casco (ca } \\
\text { siete años) }\end{array}$ & & \\
\hline $\begin{array}{l}\text { Certificado de seguridad de máquinas } \\
\text { (cada } 2 \text { años) }\end{array}$ & & \\
\hline Certificado de armamento (cada 2 añ & & \\
\hline $\begin{array}{l}\text { Certificado de seguridad radioeléctrio } \\
\text { (cada año) }\end{array}$ & & \\
\hline
\end{tabular}




\begin{tabular}{|l|l|l|}
\hline Documentación según medio de transporte & \\
\hline Diario de Máquinas & & \\
\hline Libro de Rol & & \\
\hline
\end{tabular}

Fuente: Elaboración propia según REGINAVE, (1973) y Decreto 79/98 del PEN.

Como se puede observar, la reglamentación sobre el medio fluvial es mucho más dilatada que sobre el resto de los medios. A esto se suma la documentación sobre la carga, que podemos ver en el Cuadro 15.

Cuadro 15 Documentación sobre la carga

\begin{tabular}{|l|l|l|l|}
\hline & Documentación según medio de transporte \\
\hline Convoy de empuje & Carta de porte & $\begin{array}{l}\text { Guía de removido o Solicitud } \\
\text { habilitación de servicios } \\
\text { extraordinarios }\end{array}$ & Declaración General \\
\hline Transporte ferroviario & Carta de porte & & \\
\hline Transporte carretero & Carta de porte & & \\
\hline
\end{tabular}

Fuente: Elaboración propia según REGINAVE, (1973) y Decreto 79/98 del PEN.

Con respecto a la documentación, tanto el ferrocarril como el camión solo deben contar con la "carta de porte" de la mercancía transportada al igual que el convoy de empuje, quedando suprimidos los remitos desde el año 2005. ${ }^{14}$ El Ministerio de Transportes, a través de la Dirección General de Autotransporte Federal o los Centros de la entonces Secretaría de Comunicaciones y Transporte (CST) en cada uno de las provincias podrá verificar el correcto uso de la carta de porte-traslado por parte de los transportistas a través de visitas de inspección conforme a la normatividad establecida, con independencia de la facultad que tiene la Secretaría de Gobernación a través de la Policía Federal de realizar dicha supervisión cuando las mercancías sean transportadas en vehículos o unidades motrices por los caminos y puentes de jurisdicción federal.

A este documento, el transporte fluvial suma la "Guía de removido", tramitada ante las autoridades aduaneras para mercaderías de exportación que se trasladan de un punto a otro dentro del sistema aduanero nacional, solicitada en horarios hábiles (o la "Solicitud de habilitación de servicios extraordinarios" en horarios inhábiles) en varios juegos de formularios. También una "Declaración General", que es el documento básico que

\footnotetext{
${ }^{14}$ La carta de porte es un comprobante fiscal de traslado (actualmente se obtiene de forma digital) en el que constan las mercancías que se transportan. Generalmente en ella se consigna los nombres del consignador (remitente de la mercancía) y el consignatario (receptor de la mercancía), el punto de origen, el destino, la ruta, el método de envío y el importe cobrado por la entrega. La carta de porte es el título legal del contrato entre el transportista y el expedidor o usuario que contrata el servicio por cuyo contenido se decidirán las cuestiones que ocurran sobre su ejecución y cumplimiento, será el instrumento comprobatorio de la recepción o entrega de las mercancías, de su legal posesión, traslado o transporte en el servicio de carga del autotransporte federal y que el transportista está obligado a emitir cubriendo los requisitos de la legislación de esta materia y los que corresponden al Servicio de Administración Tributaria para los efectos fiscales.
} 
proporciona la información requerida para la entrada o la salida del buque de puerto, realizada ante la Prefectura (REGINAVE, 1973, p. 98).

En lo que se refiere a los viajes, tanto el transporte automotor como ferroviario pueden fragmentar la carga, hacer trasbordo en cualquier lugar, hacer entregas y/o recibos parciales, reintegrar mercaderías, modificar recorridos e incluso utilizar la vía fluvial (para transporte entre puertos), todo ello de manera libremente ejecutada. En el transporte fluvial pueden darse las siguientes alternativas:
a) trasbordo por cambio de embarcación
b) cambio de remolcador.
c) remanentes de carga.
d) entrega en distintos puertos.

En todos los casos la documentación requerida sobre la carga debe duplicarse con los concebidos atrasos.

Finalmente tenemos el problema de la mano de obra en la logística de trasbordo de cargas (Cuadro 16).

Cuadro 16 Personal de carga y descarga y atención al vehículo

\begin{tabular}{|l|l|l|l|l|}
\hline Medio & Tipo de contratacid & Ante aduana & Ante autoridad portua & Ante prefectura \\
\hline Barcazas & Restringida & $\begin{array}{l}\text { Agencia Marítima, acre } \\
\text { ante la Aduana }\end{array}$ & $\begin{array}{l}\text { Consignatario de buq } \\
\text { habilitadas }\end{array}$ \\
\hline Ferrocarril & Libre & No aplica & No aplica & No aplica \\
\hline Camión & Libre & No aplica & No aplica & No aplica \\
\hline
\end{tabular}

Fuente: Elaboración propia según REGINAVE, (1973) y Decreto 79/98 del PEN.

Como podemos ver, mientras el ferrocarril y los camiones pueden contratarla libremente, las embarcaciones se encuentran compelidas a hacerlo dentro de un marco regulatorio mucho mayor.

\section{CONCLUSIONES}

Visto en conjunto, las carreteras, las vías navegables y los ferrocarriles componen la red de transporte terrestre de la nación. Las carreteras llevan el tráfico de camiones, en los ríos se mueven el tráfico de navíos y barcazas y los ferrocarriles transportan todo tipo de mercancías.

El transporte automotor se ha convertido en el modo más habitual en el transporte de mercancía en Argentina desafiando toda toma de decisión "racional". Sin embargo, como 
hemos podido ver hay algunas causales que lo benefician sobre otros medios de transporte. En principio por un extraordinario desarrollo de la red viaria, facilidad básica que se encuentra en el origen del problema. Esto ha llevado a un alto grado de dependencia de los transportistas que ha garantizado un nivel de injerencia política más que lo razonable. También algunas trabas administrativas para el transporte fluvial de las que están exentas el ferroviario y sobre todo el carretero. Finalmente, una orientación del servicio a las necesidades del cliente (disponibilidad, puntualidad, y flexibilidad de transporte) que no tienen los otros modos de transporte.

Por su parte, el transporte fluvial para ser optimo debe cumplir con algunas condiciones. En primer lugar, que las vías navegables tengan un adecuado dragado y balizamiento y se cuente con puertos eficientes. También que las rutas o las líneas ferroviarias sean paralelas a las vías navegables de forma de facilitar la intermodalidad. Con referencia a la distancia de origen a destino, se estima que cuanto más distante sea el trayecto más se beneficia la navegación fluvial. Se habla de 800 kilómetros para la vía fluvial, 500 para el ferroautomotor y 300 para el camión, sin embargo, consideramos que estas distancias pueden ser modificadas para el transporte fluvial si se optimiza la logística y se incrementa el volumen de carga en puerto.

Por otro lado, es necesario que el tamaño, volumen y frecuencia de las partidas de carga puedan aprovechar la máxima capacidad de transporte de los convoyes o buques. En Argentina, y sobre todo en la mesopotamia, el transporte ferroviario se encuentra casi desaparecido. Pero desde hace unos años el de barcazas ha comenzado a revivir en el norte de la provincia de Entre Ríos sobre la cuenca del Paraná.

Reiteramos que el transporte por agua casi siempre va a tener que tener un transporte previo por tierra al puerto y un transporte posterior del puerto a destino, en cambio el transporte por camión se puede realizar con entrega puerta a puerta. Debe considerarse finalmente que la duración del viaje es mayor en el transporte por agua por la menor velocidad que desarrolla, el transporte previo y posterior, las operaciones portuarias que comprende y el estado de las vías navegables.

Consideramos entonces que el uso racional de los sistemas de transporte implica un análisis holístico que determine una multimodalidad que lo aproxime a lo óptimo, pero esto implica tanto un estudio preciso de los mejores circuitos en virtud de la infraestructura disponible como de decisiones políticas que afectan a las diferentes coaliciones que se congregan en torno a las diferentes modalidades. 
Un último ejemplo, comparando el uso porcentual de los diferentes tipos de transporte en USA y Argentina es contundente (Cuadro 17):

Cuadro 17 Fletes para el transporte de 24.000 t a $500 \mathrm{~km}$ según porcentaje de medios utilizados en USA y Argentina

\begin{tabular}{|l|l|l|l|l|}
\hline \multirow{2}{*}{ Medio } & USA & Argentina \\
\cline { 2 - 5 } & $\%$ utilizado & Costo de fletes (u\$ & $\%$ utilizado & Costo de fletes (u\$d) \\
\hline Hidrovía & 25 & 60000 & 1,5 & 3600 \\
\hline Ferrovía & 50 & 240000 & 14,5 & 69600 \\
\hline Carretera & 25 & 240000 & 84 & 806400 \\
\hline Total & & 540000 & & 879600 \\
\hline
\end{tabular}

Fuente: elaboración propia en base a Campêlo \& Duhá, (2009) y Bolsa de Cereales de Entre Ríos, (2012)

El ahorro de utilizar la misma proporción que los Estados Unidos en Argentina sería del $38 \%$. Sin duda, nada desdeñable.

\section{BIBLIOGRAFÍA}

Bárbero, J.A. Serebrisky, T. (2007). Los costos logísticos ante el crecimiento del comercio exterior. Revista de la Bolsa de Comercio de Rosario, XCVII(1501). Recuperado a partir de http://agris.fao.org/agrissearch/search.do?recordID=AR2007000168

Barclay, W. S. (1917). The Geography of South American Railways. The Geographical Journal, 49(3), 161-201.

Barclay, W. S. (1932). The basin of the river Parana. The Geographical Journal, 79(2), 81-99.

BCR. (2011). Hidrovías, puertos y transporte por agua. Rosario: Bolsa de Comercio de Rosario.

Bianchi, J. (2015). Un proyecto de país. La argentina industrial. Recuperado 12 de junio de 2018, a partir de http://www.mp.gba.gov.ar/sap/hidrovia_san_pedro/Jorge_Bianchi.pdf

Bloch, R. (1999). Transporte fluvial. Buenos Aires: Ad-Hoc.

Bolsa de Cereales de Entre Ríos. (2012). Camiones, trenes y barcazas se disputan el transporte de cargas. Recuperado a partir de

http://www.bolsacer.org.ar/Fuentes/noticia.php?Id=483\&volver=13

Campêlo, M. R., \& Duhá, P. A. D. (2009). Navegação. A história do transporte hidroviário interior no Rio Grande do Sul. Rio Grande do Sul: Centhury.

Corthell, E. L. (1903). Two Years in Argentine as the Consulting Engineer of National Public Works. American Geographical Society, 35(5), 439-471. 
El Agro. (2016). La flota mercante más grande de la hidrovía está bajo dominio paraguayo. Recuperado 16 de marzo de 2018, a partir de http://www.elagro.com.py/mercados/la-flotamercante-mas-grande-de-la-hidrovia-esta-bajo-dominio-paraguayo/

Fodor, J. G., \& O’Connell, A. A. (1973). La Argentina y la economía atlántica en la primera mitad del siglo XX. Desarrollo Económico, 49, 3-65.

Friedberg, E. (1993). Le pouvoir et la règle. Dynamiques de l'action organisée. París: Le Seuil (Sociologie).

García Rodríguez, E. (2009). Infraestructura e integración en América Latina. Boletín Económico del ICE, 2974, 27-42.

Georgescu, C., \& Georgescu, P. (1998). Importancia del transporte fluvial. En Corporacion Andina de Fomento (Ed.), Los ríos nos unen. Integración fluvial suramericana (pp. 33-54). Bogotá: Editora Guadalupe Ltda.

González Climent, A. (1993). Los puertos argentinos 1950-1975. En Historia Marítima Argentina (pp. 245-260). Buenos Aires: Departamento de Estudios Históricos Navales.

Gravil, R. (1970). State Intervention in Argentina's Export Trade between the Wars. Latin American Studies, año 2, núm, 156-157.

Helman, E., Chiappe, A., Lazzarini, H., Albano, S., Malvicini, S., \& Scarabino, J. C. (2002).

Puertos y embarcaderos en el hinterland, un proyecto de crecimiento, inversión y empleo. En Séptimas Jornadas «Investigaciones en la Facultad» de Ciencias Económicas y Estadística. Rosario: UNR.

ITF. (2015). International Transport Forum - Transport Outlook 2015. Paris: OECD.

Knoepfel, P., Larrue, C., Varonne, F., \& Hinojosa Dieck, M. (2007). Hacia un modelo de análisis de políticas públicas operativo. Un enfoque basado en los actores, sus recursos y las instituciones. Ciencia Política, 3, 6-20.

List, F. (1979). Sistema Nacional de Economía Política. México: Fondo de Cultura Económica.

Mateo, J. (2007). La navegación de cabotaje en el litoral bonaerense (1840-1940). La Habana, Cuba: Instituto de Historia de Cuba.

Mateo, J. (2009). Puertos, integración y desarrollo. El sistema portuario bonaerense durante los años 1960. En J. \& A. N. Mateo (Ed.), Hablemos de puertos. La problemática portuaria desde la ciencia social (pp. 185-198). Mar del Plata: GESMar-UNMdP.

Mateo, J. (2015). Las banderas de conveniencia: ¿el huevo o la gallina de los paraísos fiscales? Desenvolvimento Socioeconômico em debate, 1(2), 127-1. 
Mateo, J. (2017a). De la insularidad a la conectividad. Los puertos de Entre Ríos (Argentina) entre 1922 y 1983”. En L. López Molina (Ed.), Cádiz al mundo: del floreciente siglo XVIII a los retos del Port of the future del siglo XXI. Madrid: Editorial Dykinson.

Mateo, J. (2017b). El granero ¿de dónde y de qué? De los granos de trigo al poroto de soja en Puerto Quequén (1970-2010). RIVAR, 4(12), 69-91.

MTU Binnenschiffe. (2017). Zentralkomitee der Binnenschifffahrt. Recuperado 18 de abril de 2017, a partir de http://www.mtu-

online.com/mtu/anwendungen/schiffsmotoren/binnenschiffe/index.de.html

Muñoz Menna, J. C. (2011). El transporte por la Hidrovía Paraguay-Paraná. Revista de la Bolsa de Comercio de Rosario, C(1515), 28-32.

Nemirovsky, L. (1933). Estructura económica y orientación política de la agricultura en la República Argentina. Menéndez.

Ortiz, R. M. (1943). Valor económico de los puertos argentinos. Buenos Aires: Losada.

Pavan, C. E. (2012a). Navegación fluvial en la cuenca del Plata. Atenea, 7, 57-81.

Pavan, C. E. (2012b). Navegación fluvial en la cuenca del Plata I. Revista guardacostas, 129, 82-96.

Poggi, A. B. (1960). Puertos y vías navegables de la República Argentina. La Dirección Nacional de Construcciones Portuarias y Vías Navegables. La Ingeniería, 978.

Puntoazul gasolineras. (2014). ¿Cuál es el consumo de los camiones de transporte?

Recuperado 30 de julio de 2017, a partir de http://puntoazul24h.es/noticias/motor/cual-es-elconsumo-de-los-camiones-de-transporte

REGINAVE. (1973). Régimen de la Navegación Marítima, Fluvial y Lacustre. Buenos Aires: Prefectura Naval Argentina.

Sabatier, P. A. (1988). An advocacy coalition framework of policy change and the role of policy-oriented learning therein. Policy Sciences, 21, 129-168.

Sábato, H. (1989). Capitalismo y ganadería en Buenos Aires : la fiebre del lanar, 1850-1890. Buenos Aires : Editorial Sudamericana.

Schurz, W. L. (1925). International Communications in South America. Council on Foreign Relations, 3(4), 624-636.

SELA. (2011). Infraestructura Física para la Integración en America Latina y el Caribe. Caracas: Sistema Económico de América Latina y el Caribe.

USCG-United States Coast Guard. (2009). The Maritime The Maritime Strategy Strategy. Washington. Recuperado a partir de http://novanavyleague.org/CS-21 Brief (Jan 09).pdf 